\title{
DO DIREITO À ATENÇÃO BÁSICA EM SAÚDE AO DIREITO À ALIMENTAÇÃO SAUDÁVEL NA ZONA DA UNASUL: REFLEXÕES SÓCIO JURÍDICAS
}

\author{
Janaína Machado Sturza* \\ Sandra Regina Martini**
}

\section{RESUMO}

O presente texto volta-se para a relação entre direito à saúde, atenção básica e alimentação saudável, no contexto da segurança alimentar, à partir dos determinantes sociais em saúde pertinentes à algumas das regiões da UNASUL. A análise estabelece-se à partir das linhas teóricas da Teoria Geral dos Sistemas Sociais de Luhmann e da Metateoria do Direito Fraterno de Eligio Resta, através de um estudo bibliográfico que segue o método hipotético dedutivo. Nesta perspectiva, identificamos a necessidade de buscar um aspecto específico da saúde e do determinante social alimentação, questão básica para que se possa falar em qualquer direito.

Palavras chave: atenção básica em saúde; determinantes sociais em saúde; segurança alimentar.

\section{FROM THE RIGHT TO BASIC HEALTH CARE TO THE RIGHT TO HEALTHY FOOD IN THE UNASUR AREA: JUDICIAL PARTNERSHIP REFLECTIONS}

\begin{abstract}
The present text focuses on the relationship between the right to health, basic care and healthy food, in the context of food security, based on the social determinants of health relevant to some of the UNASUR regions. The analysis is based on the theoretical lines of the General Theory of Social Systems of Luhmann and the Metateoria of Fraternal Right of Eligio Resta, through a bibliographic study that follows the hypothetical deductive method. From this perspective, we identify the need to seek a specific aspect of health and the social determinant of food.
\end{abstract}

Keywords: basic health care; Social determinants of health; Food security.

\footnotetext{
* Pós doutora em Direito pela UNISINOS. Doutora em Direito pela Univerisità Roma Tre, Mestre em Direito pela UNISC e Especialista em Demandas Sociais e Políticas Públicas também pela UNISC. Professora na graduação em Direito e no Mestrado em Direitos Humanos da UNIJUI, Professora na graduação em Direito da Faculdade Dom Alberto. Advogada.

*** Professora Produtividade CNPq, Pós doutora em Direito pela Univerisità Roma Tre, Pós Doutora em Política Públicas pela Università Salerno, Doutora em Direito pela Università do Salento. Professora na Graduação em Direito e no Mestrado em Direitos Humanos da Uniritter, Professora Visitante no PPGDIR/UFRGS.
} 


\section{INTRODUÇÃO}

Ao refletir-se acerca do direito à atenção básica em saúde e à alimentação saudável, tendo como referencial norteador a Teoria Geral dos Sistemas Sociais de Luhmann e a Metateoria do Direito Fraterno de Eligio Resta, pode-se verificar que a ideia de ausência de soberania nacional, a utilização pacífica dos recursos e a gestão em comum são pressupostos sempre presentes, especialmente no que tange à necessária preservação da qualidade de vida, na qual devem estar presentes benefícios para o desenvolvimento do homem e sua existência, constituindo-se como o centro de irradiação por excelência de todos os bens ou interesses jurídicos protegidos.

Ainda, quando se trata de uma sociedade contemporânea pressupõe-se que o bem saúde também seja comum, quando se trata da Constituição sem Estado fala-se em ultrapassar os limites ditados por qualquer "soberano", e, ainda, quando se ratifica a importância do pacto entre iguais - no qual o soberano não é eliminado, mas aparece como um igual - possibilitando pensar-se numa ideia da não-violência, permite-se falar em efetiva preservação do direito à saúde e, por consequência, em direito à alimentação saudável, sendo que estes direitos devem abranger toda a coletividade, estando inseridos no rol dos direitos sociais, relacionando-se à questão de o cidadão ter direito a uma vida saudável, a qual resultará em sua plena qualidade de vida.

Assim, este texto que se apresenta é decorrência das inquietações proporcionadas pelo Projeto Produtividade $\mathrm{CNPq}$ "A complexidade internacional do Direito à saúde: o caso das fronteiras do Brasil com o MERCOSUL" e do projeto de Pós doutoramento "O paradoxo teórico e normativo frente à complexidade do direito à atenção básica em saúde no Brasil: limites e possibilidade de efetivação sob a perspectiva reflexiva das teorias do Direito Fraterno e do Direito Vivo".

O que estamos apresentando aqui é a primeira parte do estudo, no qual enfocamos o referencial Teórico do projeto que envolve várias universidades e pesquisadores do Brasil e do exterior. As técnicas empregadas no projeto são a documentação, as entrevistas não-diretivas, entrevistas estruturadas, observações, grupo focal e questionários de pesquisa. A duração do projeto é de dois anos, o qual deverá iniciar a parte empírica em junho de 2017, sendo que estamos desde novembro de 2016 trabalhando na parte teórica. 
No desenvolvimento do projeto anterior, identificamos alguns temas cruciais para o entendimento e a efetivação do direito à saúde. $\mathrm{O}$ tema mais recorrente foi a relação entre direito à saúde e atenção básica e ao direito à uma alimentação saudável, pois estas se apresentam diretamente vinculadas a direitos, os quais se constituem como determinantes sociais para a saúde.

A alimentação saudável está vinculada à segurança alimentar; essa, por sua vez, é um conceito abrangente que possibilita uma visão mais integral e uma compreensão das interrelações entre as diversas dimensões da SAN (Segurança Alimentar Nutricional). Ao manter o aspecto nutricional integrado ao conceito de SAN, o Brasil adota a recomendação apresentada pelo órgão internacional Committee on World Food Security de adotar a terminologia segurança alimentar e nutricional para "refletir melhor os vínculos conceituais entre a segurança alimentar e a segurança nutricional, além de expressar um único objetivo integrado de desenvolvimento para a orientação efetiva das políticas e das ações"

Será foco do presente texto o estado da arte do direito à saúde e os determinantes sociais em saúde na UNASUL. Identificamos a necessidade de buscar um aspecto específico da saúde e do determinante social alimentação, questão básica para que se possa falar em qualquer direito, entendendo a importância da saúde e da alimentação como um bem da própria comunidade.

Desde o início do nosso estudo, identificamos a saúde como bem da comunidade vinculado ao direito à alimentação saudável. Por isso, a saúde é ponte para a cidadania, podendo ser construída com pactos, acordos e mediação. Vemos que através do direito à saúde, é possível reduzir as barreiras geopolíticas com ações fraternas, nas quais se encontra como locus privilegiado a Atenção Básica em Saúde, a qual poderá ser efetivada somente com uma alimentação saudável.

A atenção básica ou atenção primária em saúde representa uma importante estratégia para a efetivação dos direitos sociais através dos determinantes sociais em saúde, em especial o direito à alimentação saudável, condição primeira para que se possa falar em qualquer outro direito. Assim, o texto que segue apresenta os resultados parciais de um projeto envolvendo mais de 10 pesquisadores das Universidades elencadas.

\footnotetext{
${ }^{1}$ BRASIL. O Estado da segurança alimentar e nutricional no Brasil - Um retrato multidimensional. Relatório 2014. Disponível em http://www.fao.org.br/download/SOFI_p.pdf . Acesso em: março de 2017.
} 


\title{
1. A SAÚDE E SEUS DETERMINANTES SOCIAIS
}

Na sociedade contemporânea, a saúde vem sendo considerada como um bem de todos, como um direito social necessário à manutenção da vida. Entretanto, o reconhecimento de sua eficácia é um forte argumento colocado em discussão nos dias atuais, principalmente em relação aos "direitos sociais e as externalidades que não podem ser internalizadas na avaliação da saúde enquanto bem econômico" (Dallari, 1987, p. 15). Neste sentido,

\begin{abstract}
La salute è sempre stata preoccupazione primaria degli individui, elemento fondamentale del bisogno di sicurezza espresso in vari modi dalle comunità umane. La complessità degli apparati costruiti per dare una risposta a tale preoccupazione è cresciuta con la articolazione degli stati moderni, talora in forme devianti rispetto all'obiettivo originario. Le soluzione date alla domanda di cura sono diventate una parte rilevante delle politiche economiche e sociali, e al contempo sottile indicattore dello stato della democrazia nella società, cartina delle ideologie dominanti (Rossanda e Peretti, 2000, p 7)².
\end{abstract}

A saúde, então, que notadamente vem sendo analisada através de teorias tradicionais, pode também ser examinada por novas teorias, e é neste sentido que veremos a saúde através da Teoria Geral dos Sistemas Sociais de Luhmann e a Metateoria do Direito Fraterno de Eligio Resta. Mais do que uma análise do direito à atenção básica em saúde e à alimentação saudável, é importante também analisar e refletir sobre o Relatório da Comissão Nacional Sobre Determinantes Sociais da Saúde - CNDSS ${ }^{3}$.

A CNDSS foi instituída por Decreto Presidencial em 13 de março de 2006 e tem, entre outros objetivos, o de gerar informações e conhecimentos sobre determinantes sociais da saúde no Brasil, contribuir para a formulação de políticas que promovam a equidade em saúde e mobilizar diferentes instâncias do governo e da sociedade civil sobre o tema. Destaca-se o fato de ser o Brasil o primeiro país a criar uma CNDSS, e os aspectos que constam neste relatório nos fazem perceber, entre outras coisas, a necessidade de vermos o direito à saúde sob a

\footnotetext{
2 A saúde foi sempre uma preocupação primária dos indivíduos, elemento fundamental da necessidade de segurança expressa de vários modos pela comunidade humana. A complexidade dos aparatos construídos para dar uma resposta a tal preocupação é acrescida com a articulação dos estados modernos, às vezes de forma desviante do objetivo originário. As soluções dadas às questões de cura transformam-se em parte relevante das políticas econômicas e sociais, e ao mesmo tempo delicado indicador do Estado da democracia na sociedade, carta da ideologia dominante.

${ }^{3}$ Para a Comissão Nacional sobre os Determinantes Sociais da Saúde (CNDSS), os determinantes sociais em saúde - DSS - são os fatores sociais, econômicos, culturais, étnicos/raciais, psicológicos e comportamentais que influenciam a ocorrência de problemas de saúde e seus fatores de risco na população.
} 
perspectiva de pactos, de compartilhamentos, de fraternidade.

É nesta perspectiva, em conjunto com as mais diversas áreas do conhecimento que o direito moderno deve ser estudado, aplicado e refletido, e não apenas como tradicionalmente vem ocorrendo, a partir da ótica dogmática e formalista. Estudar o direito a partir de uma visão sistêmica e fraterna importa em construir um novo referencial para a própria ciência do direito, a qual deve se fundamentar em outras áreas de estudos que estão intrinsecamente ligadas "com" e "nos" fenômenos sociojurídicos.

Assim, portanto, é preciso entender que a sociedade não é simplesmente um todo orgânico integrado por partes, mas que é uma sociedade sem fronteiras, na qual os limites territoriais acabam sendo desvalorizados; é altamente complexa, contingente e paradoxal, ou, ainda, seguindo as observações de Rudolf von Jhering (2002, p 71), a sociedade é uma organização efetiva de vida para e através dos outros. Na medida em que a vida em sociedade só é possível através do reconhecimento do outro, é necessário entender as novas implicações sociais disto.

Não é difícil identificar que, nesta sociedade, todos temos muito mais direitos do que podemos efetivamente gozar. A era da inclusão universal já existe, mas sua existência está fundada em situações paradoxais nas quais, muitas vezes, a inclusão se dá pela exclusão; a possibilidade de acesso ao direito de ter direito à saúde se dá, muitas vezes, não através do sistema de saúde, mas pelo sistema judiciário, ou, ainda pior, por favores políticos ou de amizade.

Revisitar as teorias tem fundamental importância em face da complexidade que atualmente se experimenta no mundo. De acordo com Eligio Resta (2002, p. 23) ${ }^{4}$, é possível se aproximar deste mundo apenas por meio da solidariedade, uma vez que a solidão vive de separação e distância. Dessa forma, a construção de um novo mundo inserido neste já existente só é possível se buscarmos outros pilares de sustentação, que devem estar fundados na fraternidade, na solidariedade e na paz. Sem isto, a vida no mundo perde o sentido. O que é,

\footnotetext{
4 La solidarietà avvicina mondi mentre la solitudine vive di separazione e di distanze. Il movimento apparentemente si svolge a senso unico, se non cifossero spinte contraddittorie e ambivalenti; cerchiamo distanze e differenziazioni ma Le revochiamo propotentemente cercando e dando solidarietà, recongiugendo le nostre solitudine attraverso processi non soltanto simbolici che "uniscono"agli altri." A solidariedade aproxima os mundos, enquanto a solidão vive de separações e de distâncias. O movimento aparentemente desenvolve-se em sentido único, isso se não existem empurrões contraditórios e ambivalentes; procuramos distâncias e diferenciações, mas as revogamos prepotentemente procurando e dando solidariedade, restabelecendo as nossas "solidões" através de processos não somente simbólicos que "unem" os outros. Tradução livre.
} 
então, este mundo ou esta sociedade na qual exploramos, matamos, desrespeitamos, criamos guerras? É o mundo não-mundo, mas é o que temos. A pergunta seguinte é, pois: como mudar o que está dado? Como fazer com que o direito a ter direitos seja efetivado não pela via da exclusão? Esta reflexão pode ser aprofundada através da função e dos limites do direito na sociedade atual, como nos diz Stefano Rodotà (2006, p. 10):

Viviamo ormai in una law-saturated society, in una società strapiena di diritto, di regole giuridiche dalle provenzione più diverse, imposte da poteri pubblici o da potenze private, con una intensità che fa pensare, più che una necessità, a una inarrestabile deriva. La consapevolezza sociale non è sempre adeguata alla complessità di questo fenomeno, che rivela anche assimetrie e scompensi fortissimi, vouti e pieni, com um diritto invadente in troppi settori e tuttavia assente là dove più se ne avverebbe bisogno. Sostenuto da spinte diverse, e persino contraddittorie. ${ }^{5}$

Rodotà tem razão quando diz do excesso e da ausência do direito onde ele deve existir. Mais do que isso, da diversidade de regras que, ao mesmo tempo, autorizam e proíbem, assinalando, com isso, uma nova questão a ser enfrentada pelo direito a ter direito: a ambivalência da técnica, do direito. Eligio Resta vai trazer para o debate a ideia do pharmacon, ou seja, aquilo que fazemos pode tanto, e concomitantemente, servir como remédio ou como veneno, não faltando Leis e Tratados para dizer que tudo é legal.

Mediante tal contexto, não é por acaso que hoje falamos no Pacto pela Saúde, como observamos pelo próprio enunciado de tal documento - Relatório da Comissão Nacional Sobre Determinantes Sociais da Saúde - CNDSS, que afirma ser um compromisso público dos setores do SUS com base nos princípios constitucionais.

Para que todos tenham direito à saúde, é necessário efetivar o pacto pela vida, a defesa do sistema único de saúde e a gestão deste mesmo sistema. Ora, sem compartilhar com o outro como um outro-eu, é impossível pensar na vida, até porque é difícil definir seu início ou seu fim. Além desta discussão, retornando a Rodotà (2006, p. 72), outras questões ainda podem ser apresentadas:

Di chi è il corpo? Della persona interessata, della sua cerchia familiare, di un Dio che 1'há donato, di una natura che lo vuole inviolabile, di un potere sociale che in mille

\footnotetext{
${ }^{5}$ Vivemos em uma Law-satured society, em uma sociedade mais que cheia de direitos, de regras jurídicas de origens mais diversas, impostos pelos poderes públicos ou potências privadas com uma intensidade que faz do pensar, mais que uma necessidade, uma inalcançável corrente. A sabedoria social não é sempre adequada à complexidade deste fenômeno, que revela mesmo assimétrias e descompensamentos fortíssimos, vazios e cheios, com um direito que invade muitos setores e todavia não chega lá onde mais seria necessário. Sustentado por impulsos diferentes e até contraditórios. Tradução livre.
} 
modi se ne impadronisce, di un medico o di un magistrato che ne stabiliscono il destino? E di quale corpo stiamo parlando?

Queste domande rimandano ad antichi intrecci, che tuttavia continuamente si rinnovano, com soggetti vecchi e nuovi che di quel corpo quasi si contendono le spoglie. Intanto l'oggetto della contesta si moltiplica e si compone, cerca unità e conosce divisioni. In vertiginosi giochi di specchi si fronteggiano corpo fisico e corpo elettronico, corpo materiale e corpo virtuale, corpo biologico e corpo politico. Um corpo sempre più inteso come insieme di parti separate ripropone l'ipotesi dell homme machine. ${ }^{6}$

As novas políticas de saúde não podem ignorar este tipo de questionamento. É o que nos alerta o relatório da CNDSS - Comissão Nacional Sobre Determinantes Sociais da Saúde:

\begin{abstract}
A Região Nordeste, como esperado, apresenta as maiores taxas de mortalidade na infância em todos os quintis de renda, particularmente no primeiro quinto, embora a tendência histórica seja também de queda no decorrer dos anos. Se, em 1990, a taxa era de 95,7\%, declina para 64\% em 2000 e 56,4\%, em 2005. Importante destacar que, quando esse estrato é comparado com o das demais regiões do Centro-Sul, constatase diminuição nos diferenciais, no decorrer dos anos.
\end{abstract}

Ainda, seguindo as reflexões de Rodotà, podemos pensar na questão da morte, da apropriação do corpo, na cura das doenças. Quando observamos diferenças tão significativas com relação à mortalidade infantil, vemos que os determinantes sociais, aliados à ineficácia das políticas públicas, agravam a situação. "A dignidade de morrer remete a dinâmicas sociais sempre mais intricadas, e revela uma inalienável raiz tecnológica." "Quem morre? Essa é uma reflexão sobre o mundo em que vivemos, que pode produzir morte mesmo onde seria evitável" (Rodotà, 2006, p. 249). ${ }^{7}$

Pode-se também vincular as ideias de pactuação e acordo através da proposta contida no Pacto pela Saúde, ${ }^{8}$ no qual aparece claramente a necessidade de diálogo entre os mais

\footnotetext{
${ }^{6}$ De quem é o corpo? Da pessoa interessada ou da sua família, de um Deus que o doou, de uma natureza que o quer inviolável, de um poder social que de mil formas se padroniza, de um médico ou de um magistrado que estabelece o destino? E de que corpo estamos falando? Estas perguntas remetem a antigos questionamentos que continuamente renovam-se com sujeitos velhos e novos que daquele corpo quase se contém ao espoliar. No entanto, o objetivo da cortesia se multiplica e se compõe, procura unidade e conhece divisões. Em vertiginosos jogos de espelhos se confrontam corpo físico e eletrônico, corpo material e virtual, corpo biológico e político. Um corpo sempre mais entendido. Como agrupamento de partes separadas, repropõe a hipótese "homem máquina". Tradução Livre.

7 "La dignità del morire rimanda così a dinamiche sociali sempre più intricate, e rivela una ormai ineliminabile radici tecnologica." A dignidade de morrer remete a dinâmicas sociais sempre mais intricadas, e revela uma inalienável raiz tecnológica. Tradução Livre.

${ }^{8}$ PORTARIA № 91/GM DE 10 DE JANEIRO DE 2007. Regulamenta a unificação do processo de pactuação de indicadores e estabelece os indicadores do Pacto pela Saúde, a serem pactuados por municípios, estados e Distrito Federal.
} 
diversos níveis. Todos os artigos de tal Pacto nos levam a esta reflexão da continuidade, como podemos observar desde o primeiro artigo até os finais.

Art. 1ำ Instituir um único processo de pactuação, unificando o Pacto da Atenção Básica, o pacto de indicadores da Programação Pactuada e Integrada da Vigilância em Saúde - PPIVS e os indicadores propostos no Pacto pela Saúde. (...)

Art. 5o As metas pactuadas pelos municípios, os estados, o Distrito Federal e a União deverão passar por aprovação dos respectivos Conselhos de Saúde.

Art. 6o A Secretaria Estadual de Saúde deve pactuar as metas estaduais e municipais na Comissão Intergestores Bipartite (CIB) e encaminhar à Comissão Intergestores Tripartite (CIT) as metas estaduais para homologação, até 30 de março de cada ano. Parágrafo único. O Distrito Federal encaminhará suas metas à Comissão Intergestores Tripartite para homologação.

Para efetivar uma política de saúde adequada, é necessário que os atores envolvidos nela participem do processo desde sua gestão até sua implementação. É neste sentido que o direito à saúde pode ser resgatado e efetivado, pois não basta dizer que saúde é um direito do cidadão e um dever do Estado, é preciso criar condições para que este direito seja efetivado. E como isso acontecerá? Somente através de políticas públicas que apresentem uma estrutura que de fato (e de direito) contemplem todos os direitos sociais essenciais à preservação da vida do homem nesta sociedade contemporânea.

\section{A RELAÇÃO ENTRE O DIREITO À SAÚDE E À ALIMENTAÇÃo SAUDÁVEL}

Falar em atenção primária e direito à alimentação saudável implica ver os direitos implementados, ou seja, "vivos”. No que se refere aos países integrantes da União de Nações Sul-americanas - UNASUL, há um forte incentivo das Agências Multilaterais para a implementação de políticas públicas que fortaleçam ações conjuntas. Contudo, o cotidiano revela outra situação que é cada dia mais complexa e, cada vez que buscamos políticas públicas para reduzir a complexidade, vemos somente o seu aumento. Por exemplo, constitucionalmente, o Brasil garante o direito à atenção básica à saúde, assim como outros países. Entretanto, verifica-se que as políticas internas dos países membros, mesmo que possuam falhas operacionais, não privilegiam atuações em conjunto. O direito à atenção básica carece de efetividade porque seus determinantes sociais estão aquém do esperado, em especial o direito à alimentação, largamente positivado nos ordenamentos nacionais e internacionais.

No âmbito da atenção básica em saúde, uma alimentação saudável deve ser baseada em práticas alimentares que assumam a significação social e cultural dos alimentos como 
fundamento básico conceitual. Neste sentido é fundamental resgatar estas práticas bem como estimular a produção e o consumo de alimentos saudáveis regionais (como legumes, verduras e frutas), sempre levando em consideração os aspectos comportamentais e afetivos relacionados às práticas alimentares de uma povo. ${ }^{9}$

Neste contexto, percebe-se que a produção normativa na área específica do direito à saúde e alimentação saudável apresenta importantes falhas estruturais e operacionais no âmbito da UNASUL. As produções normativas sobre o tema são isoladas e, por conseguinte, não enfrentam a complexidade da relação da saúde com a alimentação saudável e o impacto no direito à saúde.

Ao analisarmos os sistemas internos de políticas públicas, identificamos que cada país membro do UNASUL tem políticas específicas. No caso do Brasil, esta proposta foi renovada com a criação do Sistema Único de Saúde, o que também ocorreu nos demais países nos seus sistemas de saúde internos, visando um acesso igualitário e universal. Ao mesmo tempo, observamos que a ausência de uma adequada atenção básica à saúde acarreta na falta de garantia de outros direitos. Isso resulta em ausência do controle social e, consequentemente num baixo nível de democracia.

Nesse sentido, a promoção e o acesso à saúde consiste num conjunto de estratégias focadas na melhoria da qualidade de vida dos indivíduos e coletividades. Pode se materializar por meio de políticas, estratégias, ações e intervenções no meio com objetivo de atuar sobre os condicionantes e determinantes sociais de saúde, de forma intersetorial e com participação popular, favorecendo escolhas saudáveis por parte dos indivíduos e coletividades no território onde residem, estudam, trabalham, entre outros. As ações de promoção da saúde são potencializadas por meio da articulação dos diferentes setores da saúde, além da articulação com outros setores. Essas articulações promovem a efetividade e sustentabilidade das ações ao longo do tempo, melhorando as condições de saúde das populações e dos territórios. ${ }^{10}$

\footnotetext{
${ }^{9}$ Informações disponíveis em: http://bvsms.saude.gov.br/bvs/dicas/211_alimentacao_saudavel.html. Acesso em: agosto de 2017.

10 Informações disponíveis em: http://dab.saude.gov.br/portaldab/ape_promocao_da_saude.php. Acesso em: agosto de 2017.
} 


\section{A POLÍTICA PÚBLICA E A CONSTITUCIONALIZAÇÃO DE DIREITOS}

Hoje, a saúde é indiscutivelmente um fundamental direito humano, além de ser também um importante investimento social. Na medida em que os governos têm o objetivo de melhorar as condições de saúde de todos os cidadãos, é necessário que invistam recursos em políticas públicas de saúde, capazes de garantirem programas efetivos para a sua promoção e consequente acesso à outros direitos, como a alimentação saudável.

Nesse sentido, as irritações sofridas pelo direito na década de 1980 para constitucionalizar o direito à alimentação, à saúde e ao trabalho é o que hoje possibilita acoplamentos, pois é a partir dos dispositivos constitucionais (em especial aquele que diz "saúde direito de todos e dever do Estado"), que permeiam o sistema do direito, que o sistema da política poderá agir, algumas vezes, como é o caso, por meio de políticas públicas de saúde.

Os fatores que influenciaram essa estreita relação entre esses sistemas são a positivação do direito e a democratização da política. Essa relação é estreita; entretanto, eles são livres de coincidências e fechados no seu operar. Assim, é possível dizer-se que a democratização da política precisa de mais proteção jurídica ao particular, especialmente no que tange ao âmbito do direito constitucional (Luhmann, 1998, p. 483).

Diante de um quadro de complexidade do ambiente, de contingência, de evolução social, foi possível acoplar isso ao direito, ou seja, os anseios político-sociais daquele momento irritaram o direito para que a saúde fosse direito de fato (expectativa normativa). Todavia, quando acontece o acoplamento estrutural entre dois sistemas, o que ocorre é uma espécie de coordenação estável das operações respectivas (Corsi, 1996, p. 20), pois, caso ocorresse tal fusão, haveria a corrupção dos sistemas, gerando o caos.

É possível observar que, a partir do acoplamento estrutural entre diversos subsistemas sociais no processo histórico de redemocratização do país, após um longo período de ditadura militar, chegou-se a uma nova conformação dos processos de comunicação social, por meio da generalização de novas expectativas normativas comuns, institucionalizadas no nível máximo constitucional. Evidencia-se isso por meio das "vitórias constitucionais" que resultaram no reconhecimento e tutela do direito à saúde, direito à alimentação, ao trabalho, ao lazer, a moradia ente outros.

No tocante ao direito à saúde e ao direito à alimentação, pode-se dizer que as suas 
expectativas normativas e a própria redefinição das funções dos Estados brasileiro, argentino, uruguaio e paraguaio, em matéria de políticas públicas de saúde previstas nas respectivas Constituições, resultam de um longo período de reordenação dos processos de comunicação e das inter-relações dos diversos sistemas sociais, marcados pela generalização de expectativas em torno da redemocratização e da redução das desigualdades sociais do país, causando um impacto concreto nas novas interações entre diversos atores sociais na luta pela concretização da saúde.

Nesse caso, pode ser registrada como "êxito político". Esse ato vai desencadear, simultaneamente, mudança na situação de vigência do direito, servindo de instrução para os tribunais, bem como para todos aqueles que queiram saber. Na sociedade de rede, um evento pode gerar demandas, consequências em outros sistemas, visto que eles estão conectados, já que a sociedade, para Luhmann, é uma rede, uma malha de comunicações.

A partir do contexto que expõe o direito à saúde ora como fruto da constitucionalização, ora como fruto de acoplamento estrutural, percebe-se que esse direito deve ser compreendido sob a ótica de um conjunto de deveres do Estado para com o cidadão, sendo que essas obrigações visam não só a minimizar ou a elidir as enfermidades, mas também garantir o pleno desenvolvimento de uma vida saudável.

A proposta do Estado de Bem-Estar Social, na UNASUL, foi incorporar a questão social, o que lhe conferiu um caráter eminentemente finalístico, propondo-lhe um caráter interventivo e promocional. Assim, o Estado Social passa a assumir funções atreladas diretamente ao seu principal ator: o indivíduo.

Pode-se dizer que esse processo de constitucionalização gerou algumas consequências jurídicas: abriu-se caminho para que todo indivíduo pudesse gozar do seu direito à saúde, visto que é um direito subjetivo, garantido pelo SUS. O direito à saúde ganhou uma perspectiva objetiva, sendo que passou a ser protegido não só pelo Estado, mas pela sociedade também, sem qualquer prejuízo do direito subjetivo, pois ainda é possível intentar ação judicial por ação ou omissão do poder público; coube ainda proteger a saúde na seara das relações privadas, no tocante ao legislativo estabelecer regras para disciplinar essas relações, mas em consonância com o respectivo texto constitucional (Manués, 2002, p. 477-478).

A constitucionalização do direito à saúde e a alimentação representaram uma tentativa de reduzir a complexidade, porque na medida em que se positiva um direito, em tese, atendese à demanda social de redução da complexidade, mas ao positivá-lo, tem-se a complexidade 
aumentada, pois, a partir disso, teremos um leque de ações que se constituem como obrigação para o Estado, e cria-se uma série de direitos advindos desse.

\section{O DIREITO À SAÚDE E À ALIMENTAÇÃO COMO BEM COMUM}

Efetivar o direito à uma alimentação saudável é reduzir as iniqüidades sociais, é eliminar as privações de liberdade, é garantir o direito universal que cada cidadão tem. Todos os países do UNASUL assinaram acordos e tratados nesse sentido. A questão é como viabilizar tais direitos, esta não é apenas uma decisão jurídico-formal, mas um fundamento ético e uma posição política no sentido de efetivar princípios como a fraternidade, hospitalidade, dignidade.

As evidências científicas demonstram que é possível readequar o modelo de desenvolvimento que temos, avaliando o impacto das novas descobertas é possível afirmar que temos condições de garantir o direito à alimentação saudável. Todavia, para isso é necessário uma reversão do modelo das políticas públicas, dando possibilidades para que todos tenham a liberdade de escolher novos rumos, sendo fundamental a alimentação saudável e adequada. As paradoxalidades que temos podem ser alteradas, é curioso ver que nos países mais pobres as pessoas estão cada vez mais obesas, isso é reflexo de uma não-cidadania, de um direito não garantido.

Temos hoje muitas possibilidades de intervenção política, através dos resultados científicos. Este é um processo complexo, mas possível, que envolve muito atores e sobre tudo as intervenções que ultrapassam as idéias do Estado-Nação, por isso, é fundamental uma atuação conjunta dos países da UNASUL, no sentido de buscarmos uma soberania alimentar e com isso a garantia de mais direitos. Esta ação implicará no fortalecimentos das democracias de cada país individualmente, bem como a America Latina. Pode ser um espaço onde a fraternidade encontre o próprio lugar e sentido, pois possibilitará a inclusão de todos, independente do lugar onde estão. O fortalecimento da UNASUL não implica em exclusão de outras realidades, ao contrário, podemos contribuir no sentido de reduzir as iniqüidades sociais através das inovações científicas e através da mobilização e participação social.

A saúde e o direito à alimentação devem ser entendidos como um bem comum da própria comunidade e os pressupostos a serem utilizados são os seguintes:

a) O bem comum como meta. Para Possenti (1991), o bem comum é sempre uma meta a ser alcançada (obiettivo da raggiungere). Com efeito, é por esse pressuposto que a 
conceituação do bem comum afasta peremptoriamente a noção de bem comum como aglutinação de bens individuais: o objetivo da sociedade não é um bem individual, mas um bem que se comunica entre todas as pessoas do grupo indistintamente. Nesse sentido, é perceptível que o direito à saúde não apenas possui um cariz individual, mas é aquele direito que diz respeito a um quadro social, que importa a coletividade, que assume uma característica transcendente àqueles que pertencem a determinada comunidade ${ }^{11}$.

b) O bem comum como fim. O bem comum é um objetivo e não um meio. É um bem intrínseco da comunidade política o qual pode e deve ser comunicável e exige a participação de todos, não no sentido utilitarista (como meio de felicidade de cada cidadão), mas como princípio de vida. Possenti o define com um communicatio in bene vivendo, o que relembra o lema da Conferência Internacional sobre Cuidados Primários de Saúde, em 1978, realizada em AlmaAta, na então União Soviética, cuja Declaração tinha uma finalidade uníssona: saúde para todos. Trata-se de um objetivo que se esperava alcançar no ano de 2000, porém ainda estamos longe de alcança-lo.

c) o bem comum em três dimensões. $O$ bem comum é composto por elementos material, intelectual e moral. Os componentes do bem comum ultrapassam (mas não prescindem) os níveis morais, éticos e políticos do bem viver. Ora, bem viver em qualquer município significa ter as condições materiais, intelectuais e morais asseguradas pela política pública que, por sua vez, é um bem comum, sendo assim, o bem viver não responsabilidade apenas dos governantes. Na área da saúde é fundamental a participação e o controle social, tão enfatizados e defendidos no nosso processo de Reforma Sanitária e depois também constitucionalizado.

d) o bem comum como justificativa da autoridade. Trata-se de um elemento conceitual importante na construção do conceito. O bem comum encontra-se fortemente vinculado a justificativa da autoridade, porquanto a legitimidade e a justiça da atuação estatal são a razão de ser do próprio poder público ${ }^{12}$. Por isso, além da dimensão local, há a dimensão

\footnotetext{
${ }^{11}$ Não se tem dúvidas sobre a dimensão social da saúde e muito mais da doença. Como exemplo podemos destacar o alcoolismo ou as doenças mentais.

12 "La non-evidenza del bene comune, il fatto che esso sia sempre soggetto ad un velo di ignoranza sono i motivi che postulano la necessità dell'autorità politica; il suo compito consiste nell'assicurare l'unità di azione del corpo politico, al cui interno generalmente esistono molteplici opinioni sugli scopi e le azioni da intraprendere ... Funzione dell'autorità è garantire l'intenzione materiale, e non solo formale, del bene comune: questo non implica che il compito delle singole persone sia sottovalutato, perché il bene comune è prodotto in tanta parte dagli sforzi cooperativi dei singoli, dal retto uso delle loro ragion pratiche, dalle infinite scelte compiute a tutti i livelli della vita sociale." POSSENTI, Vittorio. Le società liberali al bivio, Marietti, 1991. Capítulo III.
} 
global, mas sempre reforçando a própria comunidade, por isso, que é fundamental no setor saúde assegurarmos o direito à atenção básica, esta se constitui como função do município de dela decorrerão todos os demais indicadores de saúde. A Lei Federal 8080/90 buscou estabelecer a descentralização dos serviços e ações em saúde, prevendo ainda que a organização, o planejamento e o orçamento deveriam se dar de modo ascendente, de nível local ao federal, ouvidos os órgãos consultivos.

e) o bem comum e o bem público. O bem comum diz respeito à sociedade política, não somente ao Estado. Não há uma correlação entre o bem público e o bem comum. O bem público é aquele vinculado ao funcionamento da máquina estatal, da ordem pública e do direito. Entretanto, o governo como gestor do Estado também é responsável pela persecução do bem comum. A ideia de comunidade política e do próprio município significa dizer que cada cidadão é também corresponsável pela promoção do direito à saúde. Podemos observar através da informação, o quanto uma sociedade que tenha informação sobre determinada situação sanitária pode contribuir para a solução de problemas. Direito e educação devem andar juntos, não apenas no discurso político.

f) o conteúdo do bem comum. O conteúdo do bem comum não se define somente $a$ priori, mas está vinculado com outros aspectos: debate público, hábitos virtuosos, consenso e evolução social. A conceituação da saúde como bem da comunidade passa (ou passou) por esse filtro. Pela história recente, o direito fundamental à saúde foi amalgamado no texto constitucional e as formas de implementação foram previstas na legislação infrafundamentalis. Embora complexa, a sociedade contemporânea, caracterizada pelo seu caráter pluralista, acabou ampliando sua capacidade institucional de efetivar discursos, dente os quais a da participação comum. Percebe-se que a participação na organização do sistema de saúde é um exemplo de construção paulatina da saúde como bem comum de certa comunidade ${ }^{13}$.

g) o bem comum e o mérito. Para Possenti, o mérito é a medida de atuação do indivíduo no bem comum. Destaca que o bem comum não pode ser representada por uma teoria simétrica a partir do esquema de que "quem contribui mais recebe mais". Pelo contrário, a distribuição do bem comum se dá conforme as necessidades. Nesse sentido, a autoridade administrativa tem

\footnotetext{
13 “Questo è particolarmente vero per le società moderne, più complesse, più altamente differenziate, più ricche di istituzioni e di sapere, e soprattutto pluraliste, dove la partecipazione a verità comuni rimane un obiettivo auspicabile e insieme arduo. In esse difetta l'evidenza storica del bene comune perché la crisi delle primarie evidenze etiche involge, in ragione del suo carattere essenzialmente morale, difficoltà aggiuntive di discernimento dei suo contenuto concreto". POSSENTI, Vittorio. Le società liberali al bivio, Marietti, 1991. Capítulo III.
} 
o dever de realocar sua atuação de acordo a necessidade de distribuição e das carências de efetividade de direitos. O processo não prestigia as preferências, mas uma noção de finalidade compartilhada por toda a sociedade.

h) o conceito de bem comum é aberto. Para Possenti, "il concetto di bene comune come scopo della società politica è intrinsecamente proporzionale e aperto”. Em outras tintas, significa dizer que seu conceito pode ser delimitado/ampliado dentro do grupo social. De modo algum, é um conceito fechado, inalterável. Portanto, o conteúdo do bem comum é preenchível pela própria sociedade.

i) Pressupostos para a realização do bem comum. Para que o bem comum possa ser realizado de modo qualificado é imprescindível (i) instituições comprometidas com o respeito aos direitos fundamentais; (ii) que difunda a ideia de sociedade como associação e do dever de cooperação entre os indivíduos, mantendo a natural diferença intelectual e diferenças de escolha valorativas e de propósitos; (iii) a difusão da ideia de codivisão de bens, valores e fins. Esses pressupostos estribam-se no que Possenti defende ao dizer que "bene comune significa che $i$ cittadini condividono almeno alcune verità pratiche, ciò̀ una "fede pratica", alcuni fini sociali o scopi condivisi: il bene comune accomuna”. Em resumo, sem visualizar que a consecução dos bens comuns (como a saúde), são também um dever-comum (um fé-prática), que implica cooperação, não haverá sucesso no processo mediador de consecução do valor comunitário.

Estes aspectos implicam no resgate do sentido da comunidade, a qual pode ser identificada com toda a sua força e ambivalência no município. Não por acaso, sempre que se busca a efetivação do direito à saúde o município é o primeiro a ser lembrado e, muitas vezes, ao mesmo tempo, o último a ser recordado pelo "Estado-Nação", que deixa de investir em saúde em função da corrupção sistêmica.

\section{CONSIDERAÇÕES FINAIS}

Não podemos falar em direito à saúde sob a perspectiva da Teoria Geral dos Sistemas Sociais de Luhmann e da Metateoria do Direito Fraterno de Eligio Resta se não considerarmos os mais variados fatores, especialmente, neste caso, o acesso aos serviços de saúde como bem comum à toda humanidade. Nesse sentido, vislumbra-se que na paradoxalidade da sociedade contemporânea a fraternidade deve referir-se ao bom e harmônico convívio com os outros, à união de ideias e de ações, ao viver em comunidade. Daí, uma das ideias do que venha a ser o 
Direito Fraterno: é um direito que é para todos e que é aceito e/ou proposto por todos.

Todavia, falar em respeito aos direitos fundamentais, como a atenção básica em saúde e à alimentação saudável, nos remete a ideia de que a população deve estar empoderada de suas condições de vida e de seu direito a ter direitos, pois somente desta forma terá condições para enfrentar os processos de exclusão, que se fortalecem justamente quando a população não tem acesso à informação, conhecimento e educação.

Entender o direito à saúde como direito fundamental implica em pactos, acordos, codivisões; mais do que isso, é preciso retomar algumas reflexões, especialmente sobre a função do Estado em assegurar a todos os cidadãos as condições mínimas de sobrevivência, garantindo um modo de vida que não contraste com a sua saúde. Daí a importância da discussão atual sobre os determinantes sociais em saúde, embora já venha com alguns séculos de atraso.

Portanto, nesta sociedade contemporânea, falar em direito à Saúde é sinônimo de um pensamento que remete à ideia de implementação e busca da consolidação dos direitos das pessoas enquanto seres humanos, dignos de exercerem seus direitos, mas também de cumprirem seus deveres enquanto cidadãos pertencentes a um Estado de Direito. Afinal, ser cidadão é ter consciência de que se é "sujeito de direitos," direitos esses de cunho civis, políticos e sociais, dentre os quais se encontra o direito à vida e consequentemente à saúde e à alimentação saudável.

A promoção, a garantia e especialmente a efetivação do direito à atenção básica em saúde necessitam, em síntese, de estratégias que envolvam toda a população e segmentos da sociedade, em um esforço conjunto para buscar o acesso igualitário a este direito de imprescindível relevância para o pleno desenvolvimento do Estado de bem estar social. Nesta perspectiva, a análise fenomenológica, por assim dizer, do senso de juridicidade destinado a compreender o direito como uma das mais relevantes expressões da racionalidade coexistencial própria da estrutura ontológica do homem, fundamenta, por inteiro, os acontecimentos históricos da humanidade e, portanto, do direito.

Assim, a saúde como um valor supremo que atrai o conteúdo de todos os direitos fundamentais do homem, abrangendo especialmente o direito à vida, define-se enquanto a existência e o modo de ser do homem no mundo, constituindo-se como núcleo da existência humana, valor inato, imaterial, essencial, de máxima grandeza da pessoa. Logo, a sociedade contemporânea "come Stato di diritto, si è curiosamente assistito al rifiorire degli atudi e dei 
dibattiti sulla persona, sul suo valore, sul suo benessere, sulla sua qualità della vita (Petti, 1997, p. 37) $)^{14 ",}$

\section{REFERÊNCIAS}

BRASIL. O Estado da segurança alimentar e nutricional no Brasil - Um retrato multidimensional. Relatório 2014. Disponível em http://www.fao.org.br/download/SOFI_p.pdf . Acesso em: março de 2017.

CORSI, Giancarlo; BARALDI, Claudio; ESPOSITO, Elena. Luhmann in Golssario: $i$ concetti fondamentali della teoria dei sistemi social. Milano: Franco Angeli, 1996.

DALLARI, Sueli Gandolfi. A saúde do brasileiro. São Paulo Paulo: Editora Moderna, 1987.

JHERING, Rudolf von. A finalidade do Direito. Campinas: Bookseller, 2002.

LUHMANN, Niklas. El derecho de la sociedad. México: Universidad Iberoamericana, 1998.

MANUÉS, Antonio G. Moreira; SIMÕES, Sandro Alex. Direito público sanitário constitucional. Curso de Especialização em Direito Sanitário para membros do Ministério Público e da Magistratura Federal. Ministério da Saúde. Programa de apoio ao fortalecimento do controle social do SUS. Brasília: Ministério da Saúde, 2002.

PETTI, Giovanni Battista. Il risarcimento del danno biológico. Torino: UTET, 1997.

POSSENTI, Vittorio. Le società liberali al bivio, Marietti. Roma: Feltrinelli, 1991.

RESTA, Eligio. Il Diritto fraterno. Roma: Laterza, 2002.

RODOTÀ,Stefano. La vita e le regole - Tra diritto e non diritto. Milano: Feltrinelli, 2006.

ROSSANDA, Marina; PERETTI, Isabella. Il bene salute tra política e società. Roma: Editori Riuniti, 2000.

${ }^{14}$ [...]“como Estado de direito, tem-se curiosamente assistido ao reflorir dos estudos e debates sobre a pessoa, sobre seu valor, sobre seu bem estar, sobre sua qualidade de vida." Tradução Livre. 